\title{
SMART Health Technologies for Direct Patient Care
}

\author{
Thomas W Miller* \\ Professor Emeritus \& Senior Research Scientist, Institute for Health, Intervention \& Policy, University of Connecticut, Department of \\ Gerontology, College of Public Health \& Department of Psychiatry, College Medicine, University of Kentucky, USA
}

*Corresponding author: Thomas W Miller, Professor Emeritus \& Senior Research Scientist, Institute for Health, Intervention \& Policy, University of Connecticut, Department of Gerontology, College of Public Health, \& Department of Psychiatry, College Medicine, University of Kentucky, USA

\begin{tabular}{l} 
ARTICLE INFO \\
\hline Received: 㓞January 09, 2020 \\
Published: January 16, 2020 \\
\hline Citation: Thomas W Miller. SMART Health \\
Technologies for Direct Patient Care. Bi- \\
omed J Sci \& Tech Res 24(4)-2020. BJSTR. \\
MS.ID.004079.
\end{tabular}

ABSTRACT

Abbreviations: WHO: World Health Organization; AAL: Ambient Assisted Living; GOe: Global Observatory of eHealth; PDAs: Personal Digital Assistants; GPRS: General Packet Radio Service

MS.ID.004079.

\section{Opinion}

Clinical and research efforts to provide quality healthcare in the twenty-first century while addressing the challenges of an ageing population have led to multiple innovations through SMART technologies. the medical and health related professions have turned to Ambient Assisted Living [1], (AAL) which is an advanced approach that aims at helping our aging population live as independently as possible. Globally, as life expectancy continues to increase, and more and more countries are confronted with an ageing population, Smart Health technologies will need to be applied to the healthcare of older adults. So defined, Ambient Assisted Living is a multi-disciplinary approach aiming at providing an ecosystem of multiple types of mobile devices, sensors, computers, wireless networks, software applications for personal monitoring one's health and well-being and tracking through integrated telehealth systems. Ambient Assisted Living technologies provide a range from automatically switching on or off lights, electrical appliances, kitchen appliances to tracking a person's vital signs and functions and the automatic notification of medical personnel or the assistance in an emergency, first responders.

Globally, healthcare delivery systems have recognized the advantages of using Information and Communication Technology to improve the quality of healthcare education for the consumer and turning what has been recognized as traditional healthcare into Smart Healthcare. Have you ever used websites like WebMD, Mayo Clinic, familydoctor.org, healthfinder® [2], Kidshealth® [3] and MedlinePlus which provides information in both English and Spanish? Reading Health \& Wellness magazine or Living Well 60+, or Prevention is just another form of Smart Healthcare through Information and Communication Technology today

What we have come to realize is that the latest in health and medical technologies have influenced many parts of our daily life. The key concept of smart healthcare includes eHealth and mHealth services. The World Health Organization (WHO) [4] defines eHealth as: "the cost-effective and secure use of information and communication technologies in support of the health and health -related fields including healthcare, health surveillance and health education, knowledge and research.(WHO 2020) [4]" Examples of eHealth include treating patients, conducting research, educating and training the health workforce, tracking diseases and monitoring public health and providing individuals with information about their disease or medical or health condition.

The European Union extends this definition by adding that eHealth "can benefit the entire community by improving access to care and quality of care and by making the health sector 
more efficient. This includes information and data sharing between patients and health service providers, hospitals, health professionals and health information network; electronic health and medical records; telemedicine services; portable patientmonitoring devices, operating room scheduling software, robotized surgery and blue-sky research on the virtual physiological human. " The term mHealth is short for "mobile health." This term has been defined by the World Health Organization as "a component of eHealth". Since there is no standardized definition of mHealth, the Global Observatory of eHealth (GOe) has determined mHealth is "medical and public health practice supported by mobile devices, such as mobile phones, patient monitoring devices, personal digital assistants (PDAs), and other wireless devices.( mHealth 2020) [5]"

The World Health Organization through the efforts of the Secretariat have raised awareness, recorded trends, built capacity, established guidance, and generated and documented evidence on digital health, including mHealth, as a tool to promote personcentered, integrated health care service delivery. The collaboration among members has promoted public-private partnerships under recommended rules of engagement. In addition, Significant technical engagement by the Secretariat towards the development and implementation of mHealth programs have included the "Be Healthy, Be Mobile" for the prevention and management of non-communicable diseases, their comorbidities and their risk

\section{ISSN: 2574-1241}

DOI: 10.26717/BJSTR.2020.24.004079

Thomas W Miller. Biomed J Sci \& Tech Res

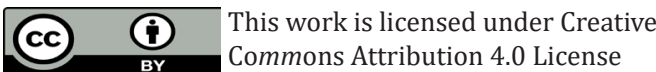

Submission Link: https://biomedres.us/submit-manuscript.php factors, including improving disease diagnosis and tracking. It has further promoted the development of guidelines for digital health interventions, including mHealth applications for health systems strengthening through the mHealth Technical and Evidence Review Group for reproductive, maternal and child health. Mobile phones and other devices are used to support patients and improve healthcare. Besides using mobile phones to make calls and sent text messages, mHealth also includes more complex features and applications such as general packet radio service (GPRS), third and fourth generation mobile telecommunications ( $3 \mathrm{G}$ and $4 \mathrm{G}$ systems), GPS and Bluetooth technology.

\section{Acknowledgement}

None.

\section{Conflict of Interest}

No conflict of interest.

\section{References}

1. (2020) Ambient Assisted Living (2020) What is Ambient Assisted Living.

2. (2020) HealthFinder.gov (2020) Live Well, Learn How.

3. Kidshealth ${ }^{\circledR}(2020)$ About Kids Health

4. (2020) World Health Organization, what is eHealth. Seventy First World Health Assembly.

5. (2020) mHealth, Use of appropriate digital technologies for public health: World Health Organization.

$\begin{array}{ll}\text { BIOMEDICAL } & \text { Assets of Publishing with us } \\ \text { RESEARCHES } & \text { - Global archiving of articles } \\ & \text { - Immediate, unrestricted online access } \\ & \text { - Rigorous Peer Review Process } \\ & \end{array}$

